\title{
Pyridine-Substituted Oligopeptides as Scaffolds for the Assembly of Multimetallic Complexes: Variation of Chain Length
}

\author{
Kristi Ohr, Brian P. Gilmartin, and Mary Elizabeth Williams*
}

The Pennsylvania State University, Department of Chemistry, 104 Chemistry Building University Park, PA 16802

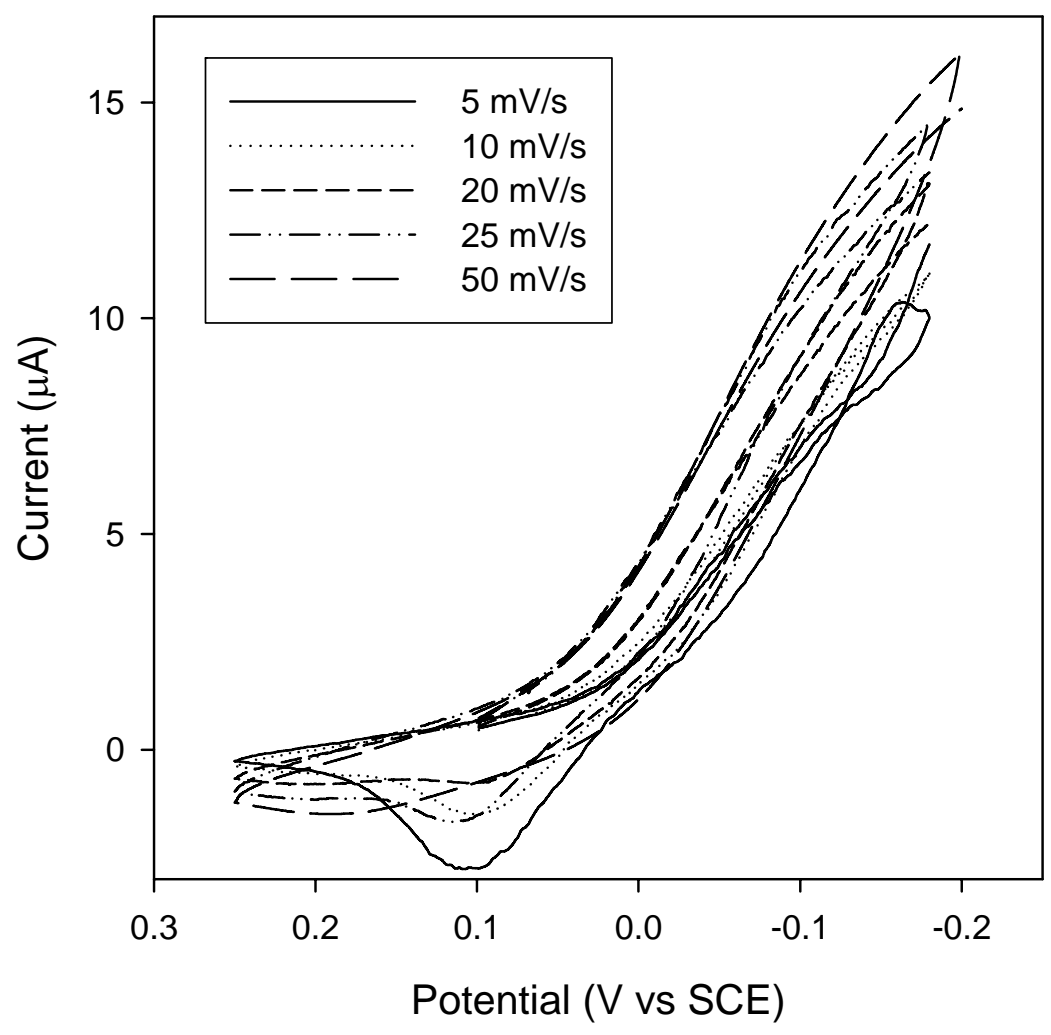

Figure S1: Cyclic voltammograms of $[\mathrm{Cu}(\mathrm{pda})]_{6}(\mathbf{6})$ at the indicated potential rates. At slow scan rates, the re-oxidation peak is more pronounced and has the characteristic shape of an adsorbed species. 


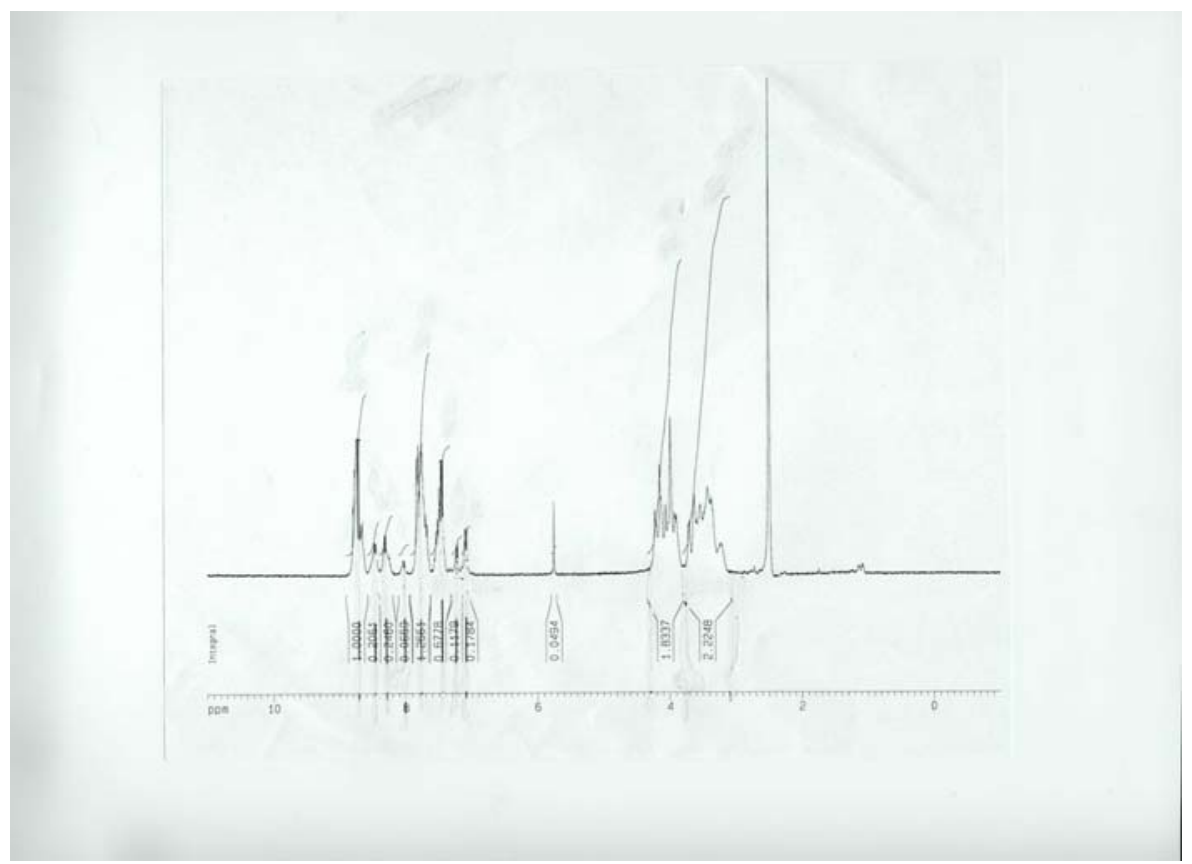

Figure S2. ${ }^{1} \mathrm{H}$ NMR of pyridine decapeptide (10) in $\mathrm{d}_{6}$-DMSO.

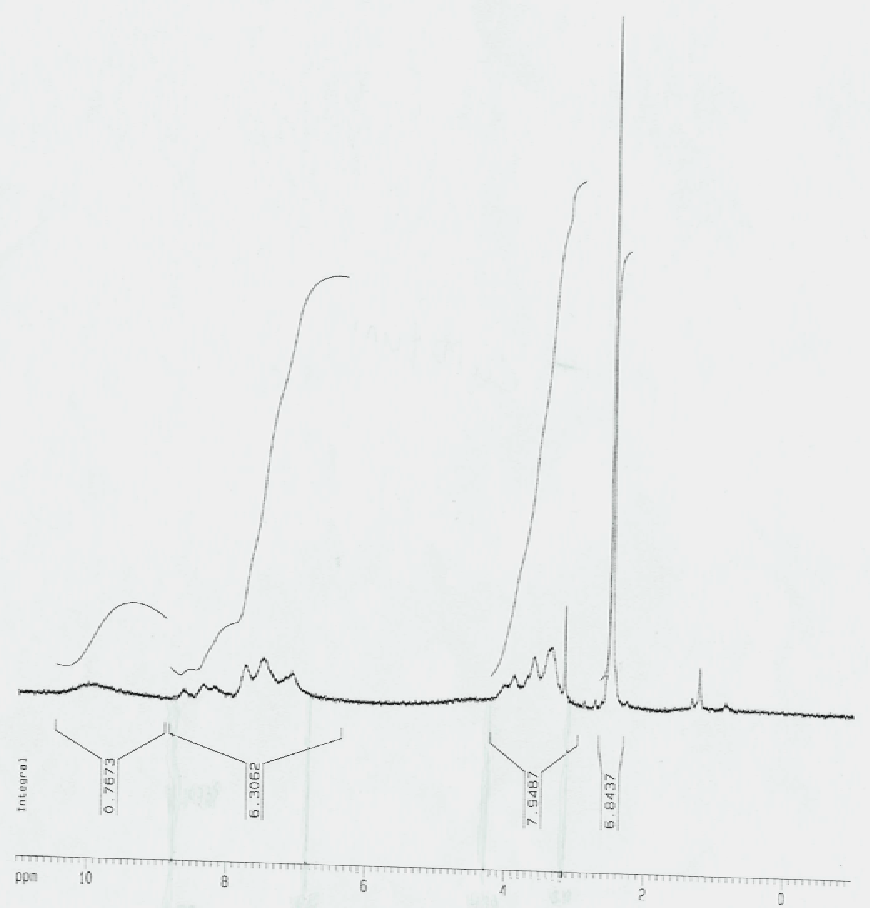

Figure S3: ${ }^{1} \mathrm{H}$ NMR of $[\mathrm{Cu}(\mathrm{pda})](\mathbf{1})$ in $\mathrm{d}_{6}$-DMSO. 


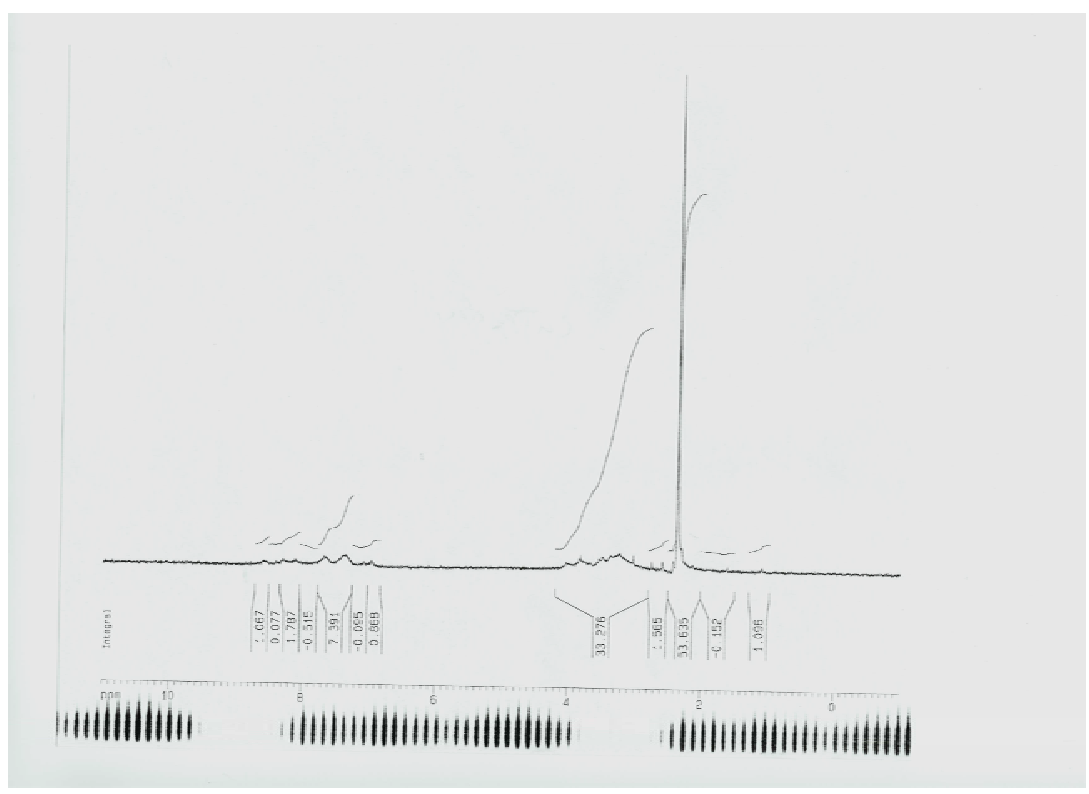

Figure S4: ${ }^{1} \mathrm{H}$ NMR of $\left[(\mathrm{Cu}(\text { tpy }))_{10}(\mathbf{1 0})\right]\left(\mathrm{ClO}_{4}\right)_{8}$ in $\mathrm{d}_{6}$-DMSO.

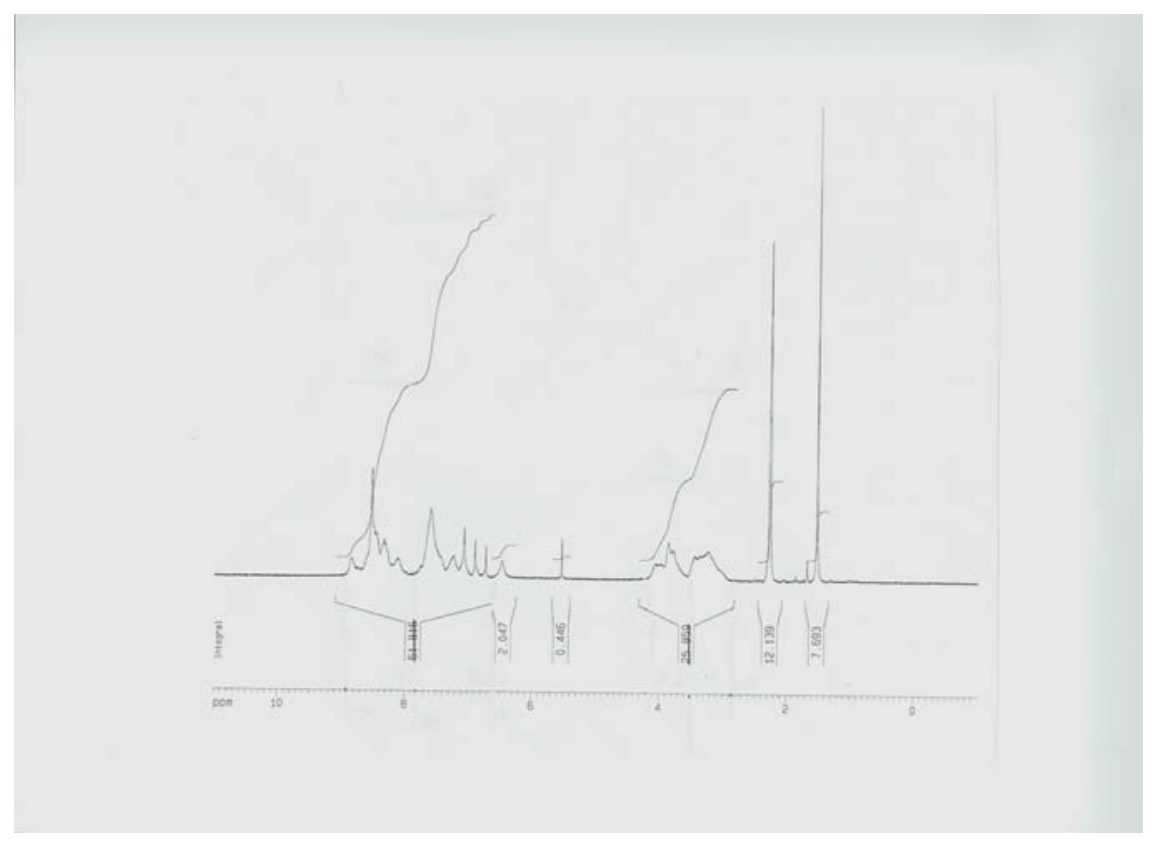

Figure S5: ${ }^{1} \mathrm{H}$ NMR of $\left[(\mathrm{Pt}(\mathrm{tpy}))_{4}(4)\right]\left(\mathrm{ClO}_{4}\right)_{8}$ in $\mathrm{d}_{6}$-DMSO 